\title{
Do Valongo ao Porto Maravilha: UMA ANÁLISE MARXISTA DA HISTÓRIA DO PORTO DO RIO DE JANEIRO
}

GONÇALVES, Guilherme Leite; COSTA, Sérgio. Um porto no capitalismo global: desvendando a acumulação entrelaçada no Rio de Janeiro. São Paulo: Boitempo, 2020. 152p.

Durante a administração de Eduardo Paes como prefeito do Rio de Janeiro (2009-2016), a prefeitura empreendeu um ambicioso projeto de revitalização da Zona Portuária da cidade, realizado sob a midiática alcunha de Porto Maravilha. O projeto consistiu na implantação de uma nova rede de infraestrutura viária e de serviços, que tinha por objetivo lançar a região como novo polo empresarial, fomentando ali um processo de adensamento demográfico e verticalização. Para tanto, em um gesto polêmico que suscitou um acalorado debate público, foi demolido o Elevado da Perimetral, que margeava o Cais do Porto e a região do Centro. A demolição foi apresentada como a obra-chave para a revitalização urbana proposta e, justamente na faixa de terrenos liberada com a remoção do elevado, foram construídos os espaços e equipamentos públicos que se transformariam nos principais símbolos da operação Porto Maravilha.

Desde o início da primeira administração Paes, foi construído em torno do projeto um denso imaginário, que criou em relação às intervenções e à própria Zona Portuária um clima de verdadeira euforia, alimentado ainda mais pela realização das Olimpíadas. Os principais produtos do Porto Maravilha foram inaugurados nos 
meses que antecederam o evento, apresentado, a partir de um dado momento, como a grande motivação daquelas obras.

O projeto de revitalização da Zona Portuária tinha como principal objeto a faixa de terrenos criada com o grande aterro, necessário à retificação do litoral, para a construção do Cais do Porto do Rio de Janeiro no início do século XX. Com esse aterro, desapareceram praias e ilhas de nomes poéticos, como a Praia Formosa e a Ilha das Moças, localizadas na região onde hoje é o bairro do Santo Cristo. Foram aterradas também importantes estruturas portuárias do século XIX, como a Estação Marítima da Gamboa, interface marítima da Estrada de Ferro Central do Brasil, e o Dique da Saúde. O grande armazém das Docas D. Pedro II perdeu o contato com o mar. Desapareceu, ainda, o vizinho Cais da Imperatriz, que havia sido remodelado e ornado com colunas e estátuas para receber a imperatriz Tereza Cristina, quando ela chegou ao Brasil em 1843. O novo Cais da Imperatriz havia sido construído sobre o Cais do Valongo, ponto de desembarque dos africanos escravizados no Rio de Janeiro até a proibição de 1831 e, como tal, elo fundamental na cadeia do rico mercado de escravos que espalhou suas estruturas pela região.

Esse processo de sucessivas reconstruções de lugares e imaginários, que acontece em uma mesma área geográfica da cidade, é também - e deliberadamente - um processo de apagamento de partes da feição preexistente daqueles lugares e de sua memória. E são justamente alguns aspectos desse processo que os sociólogos Guilherme Leite Gonçalves e Sérgio Costa se propõem a analisar no livro em questão, à luz da teoria marxista. Para os autores, a Zona Portuária do Rio de Janeiro seria uma "miniatura das metamorfoses da expansão capitalista”:

Uma espécie de lugar-síntese em que as diversas etapas históricas desse fenômeno aparecem materializadas na forma de movimentos sucessivos de incorporação e desacoplamento de tal região aos processos de transformação do espaço socialmente construído em mercadoria (p. 10).

O livro, de autoria de dois professores com carreiras consolidadas e vasto currículo de publicações, teve uma origem quase corriqueira, nascido da "tentativa 
muito despretensiosa e singela de usar o projeto Porto Maravilha para ilustrar um paper de pouco mais de quinze páginas sobre a continuidade da acumulação primitiva” (p. 10), conceito-base da teoria de Marx sobre a formação original do capitalismo. Nas palavras dos autores:

A contribuição que o livro procura prestar [consiste em] recusar os orientalismos e ocidentalismos vigentes mesmo entre autores críticos que recuperam o conceito de acumulação primitiva para estudar as mazelas do neoliberalismo. [...] Com efeito, desde o século XVI, o porto e a cidade se tornam um dos nós da teia de relações e fluxos de mercadorias e pessoas que, para a sorte de uns poucos e o infortúnio de muitos, aproximou e entrelaçou, irremediavelmente, a Europa, as Américas, a África e até mesmo a Ásia. Essa é a mensagem principal que este livro deseja transmitir (p. 11).

A argumentação está estruturada em cinco capítulos, nos quais os acontecimentos que narrei na introdução deste texto a partir do presente aparecem em ordem cronológica.

O primeiro capítulo consiste em uma análise da teoria marxista da acumulação e expansão capitalistas, até chegar ao conceito de acumulação entrelaçada, que "implica a interconexão e interpenetração não só das diferentes regiões do mundo, mas também de diferentes épocas históricas e distintas dimensões da expansão capitalista” (p. 32). Sua principal referência é o próprio livro Das Kapital, de Marx, lido com uma reverência quase litúrgica. Assim, o livro toma como base teórica o cerne da teoria de Marx: a ideia de que a produção capitalista tem como pressuposto "a transformação de bens materiais ou imateriais em valor e isto só é possível pelo 'divórcio entre os trabalhadores e a propriedade das condições de desenvolvimento do trabalho"” (pp. 13-14). Com base nessa ideia, segundo os autores, "Marx conclui que a acumulação primitiva é o 'processo histórico de separação entre o produtor e os meios de produção"” (p. 14). De acordo como essa formulação, a acumulação capitalista nasceria de um ato expropriatório, de um ato que exclui - não sem violência - uma grande massa de pessoas do processo de acumulação da riqueza e as transforma, ao mesmo tempo, em vítimas desse processo. Essa ideia dá o tom do restante do livro. Toda a história narrada tem 
como objetivo demonstrar que o porto do Rio de Janeiro foi um dos lugares onde se materializou essa exclusão.

Ainda no primeiro capítulo, são apresentadas duas questões centrais à análise que os autores fazem da trajetória do porto. A primeira é a dinâmica de sucessivos momentos de acoplamento-desacoplamento de áreas geográficas do mundo sujeitas à expansão capitalista. A segunda é o papel do Estado na acumulação capitalista, não tanto como agente regulador, mas como agente facilitador da própria acumulação, através da formulação de leis que favorecem grandes empresários e da concessão de serviços públicos à exploração por empresas privadas, especialmente visível em tempos recentes, com as chamadas parcerias público-privadas.

O segundo capítulo é breve e apresenta um panorama histórico-espacial do porto e da cidade do Rio de Janeiro, desde sua fundação até o presente. Esse panorama, focado na escala do território urbano propriamente dito, e não de sua inserção em uma rede internacional de fluxos de mercadorias, seria marcado por dois aspectos, até certo ponto contraditórios. Por um lado, pela noção, proveniente de modelos geográficos clássicos, de uma “'trajetória simbiótica', segundo a qual haveria uma 'fecundação recíproca', de modo que os portos funcionam como fator de atração e influência no sistema urbano” (p. 35). Por outro lado, por certas "disfunções que surgem nas relações entre o porto e a cidade” (p. 35).

Ao se basear em negócios "sujos" e "perigosos", do ponto de vista social e ambiental, os setores produtivos portuários dariam lugar apenas a habitações para estivadores e espaços de diversão a marinheiros e navegadores, tornando o porto a parte menos valorizada do solo e do tecido urbano [...], um mundo social, estético e político à parte (p. 36).

Para os autores, essa situação ambígua seria a marca da Zona Portuária do Rio de Janeiro, estudada de modo mais aprofundado nos três capítulos seguintes.

O terceiro capítulo narra a trajetória do porto do Rio de Janeiro desde o século XVII até 1850, a partir de uma atividade muito lucrativa, mas, digamos, bastante "peculiar" do ponto de vista social: o comércio de escravos. Os autores analisam certos aspectos internacionais desse comércio, como as vantagens 
econômicas, seu papel no fluxo de mercadorias entre três continentes e a estrutura necessária à captura daquelas pessoas na África e seu transporte até o Brasil. A seguir, evidenciam os conflitos urbanos gerados pela localização daquele comércio, que, por seu volume e pela natureza da “carga”, demandava uma grande estrutura que foi se complexificando ao longo do tempo. Esta incluía o cais para o desembarque propriamente dito, alojamentos para os cativos recém-chegados - associados às lojas onde eram comercializados -, um lazareto para isolar os doentes e até um cemitério onde eram amontoados os cadáveres dos que não resistiam à dura jornada. A presença extremamente incômoda do mercado de escravos na área mais valorizada da cidade demandou providências. Um edital de 1758 da Câmara Municipal, referendado em 1774, prescreveu sua mudança da Rua Direita (atual rua Primeiro de Março, então a via comercial mais importante da cidade) para um lugar mais afastado: o Valongo, no atual bairro da Saúde, na Zona Portuária.

Um aspecto que não aparece no livro, mas que é importante ressaltar aqui, é que essa migração, bem como a de outras atividades portuárias, para áreas mais distantes do Centro, não era o reflexo de uma migração de toda a estrutura do porto, mas de sua expansão, que levava a uma especialização do espaço urbano e portuário. Ao focarem a narrativa exclusivamente no comércio de escravos, os autores acabam perdendo de vista a complexidade funcional e a própria extensão geográfica do porto do Rio de Janeiro.

O comércio de escravos no Valongo e o cemitério são descritos em tintas vívidas, com detalhes da exposição dos corpos, mas, também, de seu enterramento precário e sua decomposição à vista dos transeuntes (pp. 67-73). É o único momento do livro em que uma descrição tão minuciosa aparece, e tem, claramente, uma função operativa no conjunto da narrativa: provocar a indignação do leitor por tal comércio, revelando a enorme injustiça social a que foram submetidas as pessoas escravizadas. Isso está em consonância com os objetivos mais amplos do livro: dar voz aos "excluídos" dos processos econômicos e sociais. Os autores o 
fazem seguindo os moldes do discurso

de Marx, que formulou sua teoria da acumulação capitalista nos termos de uma contraposição nítida de apenas duas categorias, rígidas e estanques: expropriadores e expropriados.

Ao final do terceiro capítulo, os autores apontam que a presença do mercado de escravos e do cemitério teria levado a um

Processo de gradativa desvalorização das moradias da região, que passou, cada vez mais, a ser ocupada por pessoas pobres, enquanto as demais regiões do Rio de Janeiro - como Lapa, Catete, Glória, Flamengo e Botafogo serviam às elites sempre à procura de “melhores ares” (p. 73).

Esse processo de degradação da Zona Portuária não teria sido revertido pelo fim do desembarque de escravos no local, em 1831, nem pela reforma do Cais do Valongo, em 1843, para se transformar no Cais da Imperatriz. Para os autores, a partir dos meados do século XIX,

A região vai perdendo importância como espaço da acumulação [de capital] até o início do século XX, quando será objeto das reformas urbanísticas desencadeadas pelo presidente Rodrigues Alves e pelo prefeito Pereira Passos (p. 74).
Para os autores, portanto, as grandes reformas urbanas do início do século $\mathrm{XX}$ teriam agido em uma área "desacoplada” dos fluxos do grande capital que teria de ser “remercantilizada”. Essa é, a meu ver, a passagem mais frágil, do ponto de vista historiográfico, em todo o livro. Ao fazerem essa afirmação, os autores focam na questão da habitação (com uma visão muito parcial desta), ao mesmo tempo em que desconhecem todas as grandes estruturas instaladas na Zona Portuária na segunda metade do século XIX: a Estação Marítima da Gamboa, na enseada de mesmo nome; o Dique da Saúde, onde eram reparados os navios da Lloyd Brasileiro; os moinhos Inglês e Fluminense, na altura do Morro da Saúde, ambos dotados de atracadouros próprios; o grande armazém $\mathrm{n}^{0} 5$ das Docas D. Pedro II, o único que chegou a ser construído, de um complexo portuário muito mais amplo, que deveria ter ocupado todo o litoral do bairro da Saúde. Bem longe de ter se “desacoplado" naquele período, a Zona Portuária esbanjou vitalidade econômica, talvez até estimulada pela extinção do comércio de escravos, que degradava o local. 
O quarto capítulo compreende um período longo e de muitas transformações, que começa em 1850, com a promulgação da Lei de Terras, passa pelos processos de industrialização do século XX e chega até o início do século XXI, com a implantação do projeto Porto Maravilha. Para os autores,

A região portuária, mais uma vez, funciona nesse período como um espelho que reflete de forma ampliada as mudanças no padrão de acumulação. Debilmente conectada ao processo de acumulação durante a fase industrial, busca-se, com o projeto Porto Maravilha, reintegrar a região à acumulação agora financeira do capital (p. 75).

Após comentarem brevemente alguns efeitos da Lei de Terras e as etapas do processo de industrialização-desindustrialização do Brasil, desde a segunda metade do século XIX até os anos 1990, os autores voltam a se valer da ideia de desvalorização da Zona Portuária. Dessa vez, para a construção do conceito de "Pequena África", que seria, para eles, a principal marca social da região:

Junto à desaceleração econômica, a ocupação das adjacências do porto, sobretudo nas áreas mais altas, nos morros da Providência e do Pinto, passou a ser feita cada vez mais por negras e negros alforriados e depois libertos [em 1888], [tornando-se] um espaço de sociabilidade, vivência e resistência da população pobre e negra. Ali, essas pessoas moravam em casebres, cortiços e favelas; trabalhavam nos serviços de carga e descarga do porto; professavam seus costumes, danças e religião (pp. 80-81).

Essa leitura social da Zona Portuária constitui, a meu ver, outra fragilidade do livro, porque os autores se restringem, exclusivamente, a um grupo social - de matriz africana -, desconhecendo vários outros matizes sociais da região. Ali habitavam também camadas médias da população, compostas por funcionários públicos e empregados das empresas que atuavam no porto, além de imigrantes portugueses e espanhóis, cujos descendentes, presentes na região até hoje, não se identificam com a herança cultural nem com a alcunha de "Pequena África". A distribuição espacial dos diversos

1 Para uma leitura mais complexa da estrutura social da Zona Portuária, ver o estudo antropológico sobre o Morro da Conceição feito por Roberta Sampaio Guimarães, A utopia da Pequena África: projetos urbanísticos, patrimônios $e$ conflitos na Zona Portuária carioca, Rio de Janeiro: Editora FGV, 2014. 
grupos resultou, inclusive, em uma especialização do território. De todos os morros da região, o único que se tornou "favela" foi o da Providência. Os morros do Pinto e da Conceição foram, como são até hoje, habitados por camadas médias, mas essa estratificação social não é mostrada no livro.

Com base nessa leitura social simplificada da Zona Portuária e no desconhecimento das importantes atividades econômicas que se desenvolviam na região, no livro se constrói a ideia de que,

Do ponto de vista da acumulação do capital, [...] na virada do século XIX para o XX, o espaço adjacente ao porto já se encontrava suficientemente desvinculado do mercado para constituir um estoque de possíveis ativos a serem (re)integrados aos processos de criação de valor (p. 82).

Isso teria acontecido com os melhoramentos do porto contratados durante o governo de Rodrigues Alves (1902-1906) e com as reformas urbanas realizadas no Centro do Rio de Janeiro, no mesmo período, pelo prefeito Pereira Passos. ${ }^{2}$

2 Para uma leitura mais complexa dos melhoramentos do porto do Rio de Janeiro no período Rodrigues Alves, ver
Seguindo a trilha da historiografia das reformas urbanas elaborada nos anos 1980, os autores afirmam que tais obras redundaram na expulsão maciça da população pobre que habitaria as áreas atingidas. Tal "expulsão” teria acontecido tanto na reforma do porto quanto nas obras do Centro:

A reforma Pereira Passos levou à remoção de centenas de edifícios e obras monumentais de infraestrutura com o intuito de valorizar a zona Centro-Sul da cidade do Rio de Janeiro, restando à população mais pobre se mudar para os subúrbios ou se instalar em moradias simples nos morros adjacentes ao porto reformado e renovado (p. 84).

Ao mesmo tempo,

Pereira Passos desencadeou uma política higienista e disciplinadora, penalizando comportamentos considerados incompatíveis com a cidade moderna [... e reprimindo] qualquer expressão da cultura popular local que se distanciasse de seu ideal civilizatório (p. 84).

O foco dessa política teria sido justamente os representantes da

Maria Cecília Velasco e Cruz, "O porto do Rio de Janeiro no século XIX: uma realidade de muitas faces", Revista Teтpo, no 8 (1999), pp. 123-147. 
"Pequena África”, que aparecem, no discurso dos autores, duplamente expropriados. Por um lado, teriam perdido seus espaços de moradia e sido obrigados a se alojar em lugares menos favorecidos. Por outro, suas práticas culturais teriam sido duramente reprimidas, em nome de uma suposta "civilização".

Essa ideia, bastante difundida na historiografia, não resiste ao estudo da documentação primária das reformas urbanas de Pereira Passos. Isso acontece porque os alargamentos de ruas projetados ocorreram, sobretudo, nas áreas mais centrais e valorizadas da cidade, nas freguesias da Candelária (onde foi construída a grande Avenida Central) e do Sacramento, onde não havia residências de população pobre. ${ }^{3}$ Portanto, a "expulsão" dos pobres por causa das reformas urbanas precisa ser redimensionada, porque os pobres residiam em áreas periféricas ao Centro - Cidade Nova, Zona Portuária, Morro do Castelo que não foram atingidas pelas obras,

3 Para uma leitura mais complexa das reformas Pereira Passos, ver Paula De Paoli, Entre relíquias e casas velhas. A arquitetura das reformas urbanas de Pereira Passos no Centro do Rio de Janeiro, Rio de Janeiro: Rio Books, 2013. ou o foram em uma medida muito reduzida (cito, por exemplo, o pequeno corte no Morro do Castelo para a abertura da Avenida Central - não confundir com o arrasamento total do morro em 1922 - que, de fato, comportou a demolição de algumas habitações de população pobre, na subida da ladeira do Seminário). Nessas áreas periféricas, não era tão necessário reprimir os costumes “incivilizados", porque eram quase um mundo à parte, como são, em grande medida, as favelas de hoje. Na realidade, o ambiente de "civilização” foi um cenário construído em uma área muito restrita da cidade.

Depois de narrar brevemente um novo processo de desmercantilização da Zona Portuária, no final do século $\mathrm{XX}$, os autores chegam finalmente ao projeto Porto Maravilha, mais uma vez lançando mão da teoria marxista para desenvolver sua crítica, o que acontece sob dois vieses. Em primeiro lugar, uma crítica ao meio de financiamento do projeto, um artifício econômico criado pela prefeitura que elevou o gabarito anteriormente baixo da região para até 50 pavimentos. Para lançar mão desse potencial construtivo adicional, 
os interessados deveriam adquirir os chamados Cepacs (Certificados de Potencial Adicional de Construção). Reforçando ainda mais o caráter de artifício da operação financeira, em uma frase que se tornou célebre, o prefeito declarou: “...e eu inventei de vender o ar". Os títulos foram disponibilizados em leilão público e adquiridos, em lote único, pela Caixa Econômica Federal, utilizando recursos do FGTS. Com os recursos assim obtidos, foi contratado um consórcio para realizar as grandes obras públicas de infraestrutura necessárias à requalificação da região, e também a prestação de serviços públicos, por um período de quinze anos, ainda em vigor em 2020, por meio de uma parceria público-privada. Por uma questão de espaço, não reproduzirei aqui a riqueza de detalhes que o livro traz da operação. Basta dizer que o FGTS, ou seja, os trabalhadores brasileiros, arcaram com todos os riscos de seu insucesso, e que as empresas que formam o consórcio encontram-se envolvidas em vultosos escândalos de corrupção.

O segundo viés da crítica é a expulsão da população local que teria sido promovida pelas obras do Porto
Maravilha, apresentada em termos de uma contraposição um tanto esquemática entre os herdeiros da chamada “Pequena África” e o grande capital que moldou aquela operação financeiro-imobiliária. Para os autores, os terrenos da Zona Portuária foram considerados um "vazio" a ser ocupado por novos edifícios, pessoas e funções. Essa retórica tornaria invisíveis os antigos moradores, justamente os representantes da "Pequena África”, que teriam sido alvo de violências e remoções. Mais uma vez, a narrativa desconhece a complexidade da estratificação social da região pois, à exceção do morro da Providência, os demais são habitados por camadas médias que têm bem pouco a ver com a herança cultural africana. Além disso, assim como nas reformas Pereira Passos, a ideia de “expulsão” precisa ser relativizada, porque a operação imobiliária do projeto Porto Maravilha teve como foco a área plana da Zona Portuária a faixa de aterro construída com os melhoramentos do porto no início do século $\mathrm{XX}$, que quase não tinha moradores (esse "quase" se refere a alguns velhos armazéns invadidos, muito poucos, na verdade. Nem todos 
foram desocupados pelo projeto, e mantêm seus habitantes até hoje). Ao mesmo tempo, quase toda a população da região se concentra nos morros e nas raras áreas planas preexistentes ao aterro, que foram pouco atingidas pelas obras e conservam as antigas edificações e seus habitantes.

O quinto capítulo narra a maneira como a crise econômica mundial atingiu a área do Porto Maravilha, desde 2015, levando ao fracasso da política imobiliária proposta. Esse fracasso, para os autores, resultaria em novas expropriações, sob dois vieses principais. Por um lado, a falta de interesse em adquirir os Cepacs gerou um grande prejuízo para o FGTS, a ser repartido entre os trabalhadores brasileiros. Por outro, a permanência do vazio da área geraria um novo espaço a ser apropriado pelo grande capital, o que resultaria em novas expropriações da população residente e em novas violências simbólicas contra sua cultura. Trata-se, aqui, apenas de uma hipótese que os autores fazem sobre o futuro do projeto Porto Maravilha, porque o momento atual é de absoluta estagnação.
A maneira como os autores se apropriaram da teoria marxista, no livro em questão, apresenta dois aspectos que me parecem especialmente dignos de nota. Em primeiro lugar, dá lugar a um discurso abertamente ideológico: ao denunciarem o ato expropriatório original identificado na base da acumulação capitalista, eles pretendem conferir visibilidade aos "excluídos" dos processos de acumulação. Em segundo lugar, trata-se de um discurso até certo ponto contraditório. Por um lado, revela-se muito sofisticado ao descrever mecanismos econômicos e fluxos de capitais. Por outro, é altamente simplificador dos processos históricos e sociais analisados. Ao aniquilarem, na narrativa, a multiplicidade dos sujeitos identificados como “excluídos” e suas visões de mundo, os autores os reduzem a um único grupo social, rígido e estanque, contraposto, um tanto mecanicamente, a um fluxo abstrato de capitais e estruturas de poder. O livro traz, assim, um discurso que dá visibilidade aos “excluídos”, mas ao mesmo tempo os oculta, porque lhes tolhe o caráter de sujeitos. 
Esses aspectos se traduziram em algumas opções narrativas.

Em primeiro lugar, na leitura redutiva da própria história da Zona Portuária, que os autores afirmam logo na introdução:

O interesse também não é, certamente, historiográfico. O uso que se faz no livro da bibliografia sobre a história do porto e da cidade do Rio de Janeiro, tão volumosa como sofisticada, é pontual e seletivo, destacando-se apenas alguns dos aspectos e debates que permitem elucidar o argumento desenvolvido (p. 11).

A opção por estudar a história da região de forma superficial, abrangendo um arco temporal muito longo a partir de poucas fontes secundárias, resulta em uma narrativa idealizada e esquemática, onde a contraposição das categorias "expropriadores" e “expropriados” se torna mais importante do que os processos históricos. Resulta também em algumas falhas na leitura desses processos, como a ideia de que a região esteve "desacoplada” dos fluxos do grande capital na segunda metade do século XIX, desconhecendo todas as importantes estruturas portuárias e produtivas que ali se instalaram naquele período.
Em segundo lugar, na opção por abordar o tema da escravidão (e, indiretamente, do negro) a partir de um aspecto muito peculiar, embora decisivo: o comércio dos africanos escravizados na praça do Rio de Janeiro. Esse aspecto permite aos autores "aplicar" o conceito de acumulação entrelaçada, pois era fruto de uma rede de acumulação de capital que envolvia a Europa, o Brasil e a África. Mas, ao mesmo tempo, é o aspecto que mais "coisifica” o escravo, pois o transforma em mera peça a ser vendida, enquanto existiam muitos outras dimensões do ser negro - e do ser escravo - no Brasil oitocentista.

Em terceiro lugar, temos aqui uma leitura extremamente limitada dos grupos sociais que habitavam e habitam a Zona Portuária, reduzidos a apenas um: os indivíduos de origem africana que teriam dado lugar a uma “Pequena África” na região. Esse grupo aparece, na narrativa, mecanicamente contraposto, tanto às reformas urbanas do início do século XX, quanto às intervenções do Porto Maravilha. Esse esquematismo oculta uma série de outros grupos locais, com outras expectativas e visões de mundo. Quanto ao projeto Porto Maravilha, um 
grupo social bastante prejudicado foi o dos grandes comerciantes antes ali instalados, que tiveram seus negócios inviabilizados pelas intervenções (alguns chegaram a fechar as portas, e outros sobrevivem com muitas dificuldades). Como a propalada revitalização não aconteceu, a Zona Portuária tem hoje menos atividade econômica do que tinha antes das obras, mas o único aspecto que aparece no livro bastante amplificado em relação ao que ocorreu - é a "remoção" da população negra e pobre.

Por fim, a opção pela análise da área com base em um abstrato fluxo de capitais silenciou (e esterilizou), na narrativa, o farto imaginário mobilizado em torno das obras do Porto Maravilha, que quase não aparece no texto. Com esse tipo de abordagem, os autores deram pouco espaço à euforia que, embora feita de uma substância tão rarefeita e volátil quanto o ar que o prefeito vendeu, é uma das componentes mais marcantes daquele projeto.
Apesar desse silêncio, os autores incorporaram, sem nenhum questionamento, uma das máximas desse imaginário: a ideia de que as obras do Porto Maravilha foram obras olímpicas. Na realidade, o projeto fora lançado antes da escolha do Rio de Janeiro para sede da Olimpíada de 2016 e conduzido com dotação orçamentária própria. Não é possível saber qual teria sido o papel do projeto Porto Maravilha no imaginário urbano sem os jogos olímpicos. No entanto, ao reduzirem os processos urbanos a mero fluxo de capitais financeiros, que esmagaria certos grupos sociais, lidos de forma redutora, a obra silenciou sobre um processo de significações e construções do espaço urbano muito mais complexo, pois resultado do entrelaçamento das ações de diversos sujeitos sociais, suas expectativas e memórias. Toda história é feita de luzes e sombras.

\section{Paula De Paoli (D)}

